\title{
Comment On: Survival and Quality of Life Following Cytoreductive Surgery Plus Hyperthermic Intraperitoneal Chemotherapy for Peritoneal Carcinomatosis of Colonic Origin
}

\author{
Antonio Pinna, MD ${ }^{1}$, Alan S. Rosman, MD, FACP ${ }^{2}$, and Marcovalerio Melis, MD, FACS ${ }^{1}$ \\ ${ }^{1}$ Division of Surgical Oncology, Department of Surgery, New York University School of Medicine, New York, NY; \\ ${ }^{2}$ Division of Gastroenterology, Department of Medicine, Mount Sinai School of Medicine and Bronx VAMC, New York, \\ NY
}

\section{TO THE EDITORS:}

We read with great interest the article by Hill et al. published in Annals of Surgical Oncology. ${ }^{1}$ We congratulate Dr. Levine's group as they have brought many contributions to the treatment of peritoneal malignancies, and continue to shed light on this challenging field. In the article, the authors have used several well-validated tools and questionnaires to assess changes in quality of life (QOL) after cytoreductive surgery (CS) and hyperthermic intraperitoneal chemotherapy (HIPEC) for carcinomatosis of colonic origin. Over the course of the 12 months following surgery, little non-significant variation from baseline was observed in QOL scores, with the only exception being emotional well-being. The authors concluded that survival can be attained without major decrements in QOL at 1 year.

We would like to point out that the data presented in the article do not fully validate this statement. From Table 2, it is readily apparent that only a small portion of patients for whom baseline was available $(n=61)$ were included at subsequent follow-ups: 33 (54\%) at 3 months, $27(44 \%)$ at 6 months, and merely $19(31 \%)$ at 1 year. It is well-known that baseline global QOL scores are among the strongest predictors of long-term overall survival for patients with locally advanced cancer. ${ }^{2-3}$ Patients with the highest QOL scores at baseline were most likely to live longer and were therefore most likely to be included in the 12-month follow-up. On the other hand, patients with poor QOL scores at baseline were more likely to die (or at least be too sick to reply to the follow-up questionnaires), and therefore more likely to be progressively excluded from follow-up assessments, with the final effect of artificially increasing the QOL scores in the surviving patients.

The authors should have performed an analysis on the subset of patients who survived 6 months $(n=27)$ and those who survived 12 months $(n=19)$ to look at the respective 6 or 12 month effects of HIPEC on QOL. With this type of analysis, we would have probably observed a steady and significant decrease in QOL from baseline.

\section{REFERENCES}

1. Hill AR, McQuellon RP, Russell GB, et al. Survival and quality of life following cytoreductive surgery plus hyperthermic intraperitoneal chemotherapy for peritoneal carcinomatosis of colonic origin. Ann Surg Oncol. 2011;18:3673-79.

2. Movsas B, Moughan J, Sarna L, et al. Quality of life supersedes the classic prognosticators for long-term survival in locally advanced non-small-cell lung cancer: an analysis of RTOG 9801. J Clin Oncol. 2009;27:5816-22.

3. Qi Y, Schild SE, Mandrekar SJ, et al. Pretreatment quality of life is an independent prognostic factor for overall survival in patients with advanced stage non-small cell lung cancer. $J$ Thorac Oncol. 2009;4:1075-82.
(C) Society of Surgical Oncology 2017

First Received: 13 October 2017;

Published Online: 3 November 2017

M. Melis, MD, FACS

e-mail: mvmelis@hotmail.com 